\title{
Arterial structure and function and environmental exposure to cadmium
}

R Schutte, T Nawrot, T Richart, L Thijs, H A Roels, L M Van Bortel, H Struijker-Boudier and J A Staessen

Occup. Environ. Med. 2008;65;412-419; originally published online 19 Oct 2007; doi:10.1136/oem.2007.035576

Updated information and services can be found at:

http://oem.bmj.com/cgi/content/full/65/6/412

\section{These include:}

References This article cites 48 articles, 11 of which can be accessed free at: http://oem.bmj.com/cgi/content/full/65/6/412\#BIBL

Rapid responses You can respond to this article at:

http://oem.bmj.com/cgi/eletter-submit/65/6/412

Email alerting Receive free email alerts when new articles cite this article - sign up in the box at service the top right corner of the article

Notes 


\title{
Arterial structure and function and environmental exposure to cadmium
}

\author{
R Schutte, ${ }^{1,2}$ T Nawrot, ${ }^{1}$ T Richart, ${ }^{1}$ L Thijs, ${ }^{1}$ H A Roels, ${ }^{3}$ L M Van Bortel, ${ }^{4}$ H Struijker- \\ Boudier, $^{5} \mathrm{~J}$ A Staessen ${ }^{1}$
}

${ }^{1}$ Studies Coordinating Centre, Division of Hypertension and Cardiovascular Rehabilitation, Department of Cardiovascular Diseases, University of Leuven, Leuven, Belgium; ${ }^{2}$ Subject Group Physiology, North-West University (Potchefstroom Campus), Potchefstroom, South Africa; ${ }^{3}$ Industrial Toxicology and Occupational Medicine Unit, Université catholique de Louvain, Brussels, Belgium; ${ }^{4}$ Heymans Institute of Pharmacology, Ghent University, Ghent, Belgium;

${ }^{5}$ Department of Pharmacology and Toxicology, Cardiovascular Research Institute, Maastricht University, Maastricht, The Netherlands

Correspondence to: Dr Jan A Staessen, Studies Coordinating Centre, Laboratory of Hypertension, University of Leuven, Campus Gasthuisberg, Herestraat 49, bus 702 , B-3000 Leuven, Belgium jan.staessen@med.kuleuven.be

Accepted 16 October 2007 Published Online First 19 October 2007

\section{ABSTRACT \\ Objectives: Few studies have addressed the effect of cadmium toxicity on arterial properties.}

Methods: We investigated the possible association of $24 \mathrm{~h}$ urinary cadmium excretion (an index of lifetime exposure) with measures of arterial function in a randomly selected population sample $(n=557)$ from two rural areas with low and high environmental exposure to cadmium.

Results: 24 h urinary cadmium excretion was significantly higher in the high compared with the low exposure group ( $p<0.001)$. Even though systolic ( $p=0.42)$, diastolic $(p=0.14)$ and mean arterial pressure $(p=0.68)$ did not differ between the high and low exposure groups, aortic pulse wave velocity ( $p=0.008)$, brachial pulse pressure $(p=0.026)$ and femoral pulse pressure $(p=0.008)$ were significantly lower in the high exposure group. Additionally, femoral distensibility $(p<0.001)$ and compliance $(p=0.001)$ were significantly higher with high exposure. Across quartiles of $24 \mathrm{~h}$ urinary cadmium excretion (adjusted for sex and age), brachial (p for trend $=0.015$ ) and femoral ( $p$ for trend $=0.018$ ) pulse pressure significantly decreased and femoral distensibility ( $p$ for trend $=0.008$ ) and compliance ( $p$ for trend $=0.007$ ) significantly increased with higher cadmium excretion. After full adjustment, the partial regression coefficients confirmed these associations. Pulse wave velocity $(\beta=-0.79 \pm 0.27 ; p=0.004)$ and carotid $(\beta=-4.20 \pm 1.51 ; p=0.006)$, brachial $(\beta=-5.43 \pm 1.41 ; p=0.001)$ and femoral $(\beta=-4.72 \pm 1.74 ; p=0.007)$ pulse pressures correlated negatively, whereas femoral compliance $(\beta=0.11 \pm 0.05 ; p=0.016)$ and distensibility $(\beta=1.70 \pm 0.70 ; p=0.014)$ correlated positively with cadmium excretion.

Conclusion: Increased cadmium body burden is associated with lower aortic pulse wave velocity, lower pulse pressure throughout the arterial system, and higher femoral distensibility.

Cadmium is a ubiquitous pollutant which persists in the environment. It accumulates in the body, especially the kidney, ${ }^{1}$ and is highly toxic. It is implicated in renal dysfunction, ${ }^{2-4}$ increased calciuria, ${ }^{5}$ osteoporosis $^{67}$ and the development of cancer. ${ }^{8}$ Indeed, $24 \mathrm{~h}$ urinary cadmium excretion is regarded as the most reliable biomarker of lifetime exposure. 9 Studies on the influence of cadmium on the cardiovascular system in environmentally exposed populations are limited and contradictory. In a multivariate-adjusted analysis of a population cohort, $24 \mathrm{~h}$ urinary cadmium excretion was not associated with increased conventional or $24 \mathrm{~h}$ ambulatory blood pressure or increased risk for hypertension. ${ }^{10}$ Recently NavasAcien et $a l^{11}{ }^{12}$ reported that peripheral arterial disease, defined as an ankle-brachial index below 0.9 , was associated with cadmium in blood ${ }^{11}$ and spot urine samples. ${ }^{12}$ In a previous short report, $w^{13}$ confirmed an inverse association between the ankle-brachial index and blood cadmium, but we could not reproduce this association with $24 \mathrm{~h}$ urinary cadmium excretion. No information is currently available on the associations of more elaborate measures of arterial function (as opposed to ankle-brachial index) and the cadmium body burden. In view of the above-mentioned limitations, we investigated in a random population sample to what extent the properties of large arteries are related to $24 \mathrm{~h}$ urinary cadmium excretion.

\section{METHODS}

\section{Study population}

The Ethics Committee of the University of Leuven approved the study. We recruited a random sample of households from two rural areas located in the northeast of Belgium, close to the border with The Netherlands. One region had an estimated population of 9840 inhabitants and was close to three zinc/cadmium smelters, while the other had 9390 inhabitants and was less polluted by cadmium. In the two areas, the geometric mean cadmium concentration in soil sampled from kitchen gardens averaged $5.3 \mathrm{ppm}$ and $0.9 \mathrm{ppm}$, respectively $(\mathrm{p}<0.001) .{ }^{14}$ All household members aged 20 years and over were invited to take part. The participants gave informed consent in writing. Of 590 subjects examined, we excluded 33 subjects who were missing necessary basic variables from all analyses. The participation rate among the subjects contacted was $64.3 \%$.

\section{Clinical measurements}

From April 1991 to February 1994, we examined the participants at a locally organised clinic. The subjects refrained for at least $3 \mathrm{~h}$ from heavy exercise, smoking and drinking alcohol or caffeinecontaining beverages. Trained nurses measured blood pressure and anthropometric characteristics. They administered a questionnaire to collect information about the participant's lifestyle and intake of medications. Socio-economic status was coded $^{15}$ and condensed into a scale with scores that ranged from 1 to 3 . By use of published tables, ${ }^{16}$ energy spent in physical activity was calculated from body weight, time devoted to sports and work, and type of physical activity. Blood pressure 
was the average of five consecutive clinic readings. Pulse pressure was the difference between systolic and diastolic blood pressure. Mean arterial pressure was diastolic plus one third of pulse pressure. Body mass index was defined as weight in kilograms divided by the square of height in meters.

\section{Arterial measurements}

With subjects lying in the supine position and by means of a pulsed ultrasound wall tracking system (Wall Tracking System, Pie Medical, Maastricht, The Netherlands), one trained researcher obtained vascular measurements at the common carotid artery $2 \mathrm{~cm}$ proximal of the carotid bulb, at the femoral artery $1 \mathrm{~cm}$ proximal of the bifurcation into the profound and superficial branches, and at the right brachial artery $2 \mathrm{~cm}$ proximal of the antecubital fossa. ${ }^{17} 18$ The observer also determined carotidfemoral pulse wave velocity from the length of the carotidfemoral segment and the transit time of the pulse wave. The length of the carotid-femoral segment was calculated as the difference of the distances between the site of the carotid ultrasound measurement and the suprasternal notch and between the suprasternal notch and the site of the femoral measurement. Also, for ankle-brachial index determinations, right brachial artery and right posterior tibial artery systolic blood pressures were each the average of two Doppler readings (D104 flowmeter, BV105B, Oxford Sonicaid, Chichester, UK) at each site.

During the ultrasound examination, an automated oscillometric device (Dinamap 845, Critikon, Tampa, FL) recorded blood pressures at the subject's upper arm at $5 \mathrm{~min}$ intervals. As for the conventional auscultatory measurements, cuff size was adjusted to the circumference of the upper arm. ${ }^{19}$ Standard cuffs had an inflatable $12 \times 24 \mathrm{~cm}$ bladder. If arm girth exceeded $31 \mathrm{~cm}$, larger cuffs with a $15 \times 35 \mathrm{~cm}$ bladder were utilised.

As described elsewhere, ${ }^{20}$ the observers applied applanation tonometry with a pencil-shaped probe (Millar Instruments, Houston, TX) calibrated to mean and diastolic blood pressure at the brachial artery to derive the local pulse pressure at the other arteries. We computed the cross-sectional compliance (CC) and the distensibility coefficient (DC) from the diastolic cross-sectional area $(\Delta \mathrm{A})$ and the local pulse pressure $(\Delta \mathrm{P})$ : $\mathrm{CC}=\Delta \mathrm{A} / \Delta \mathrm{P}$ and $\mathrm{DC}=(\Delta \mathrm{A} / \mathrm{A}) / \Delta \mathrm{P} . \mathrm{A}$ and $\Delta \mathrm{A}$ were calculated as $\mathrm{A}=\pi \times(\mathrm{D} / 2)^{2}$ and $\Delta \mathrm{A}=\pi \times[(\mathrm{D}+\Delta \mathrm{D}) / 2]^{2}-\pi \times(\mathrm{D} / 2)^{2}{ }^{21}$

\section{Biochemical measurements}

The participants collected a $24 \mathrm{~h}$ urine sample in a wide neck polyethylene container. A venous blood sample was obtained within 2 weeks of the clinic visit and $24 \mathrm{~h}$ urine collection. By means of standard automated techniques, blood was analysed for glucose, the serum concentrations of total cholesterol and highdensity lipoprotein (HDL) cholesterol, and the activity of $\gamma$ glutamyltransferase, as an index of alcohol intake. Blood cadmium and $24 \mathrm{~h}$ urinary cadmium concentrations were measured with an electrothermal atomic absorption spectrometer equipped with a stabilised temperature platform furnace and Zeeman background correction. ${ }^{22}$ In an external quality control program completed by Trace Element Control Scheme (organised by Robens Institute, University of Surrey, UK), the accuracy of the cadmium measurements did not show any significant time trend. ${ }^{23}$

\section{Statistical analysis}

For database management and statistical analysis, we used SAS software version 9.1 (SAS Institute, Cary, NC). The distributions of $\gamma$-glutamyltransferase, blood cadmium and urinary cadmium were normalised by logarithmic transformation. We compared means by a standard normal z test. After stratification for exposure area, we subdivided the distribution of $24 \mathrm{~h}$ urinary cadmium excretion into quartiles. With adjustments applied for sex and age, we plotted the arterial measurements by quartiles to ensure that there was no threshold phenomenon and that linear correlation techniques were appropriate. Next, we investigated associations between outcome and exposure variables in the total group, using single and multiple linear regression analyses. We identified covariates by a stepwise regression procedure with $\mathrm{p}$ values for variables to enter and to stay in the model set at 0.15 . Covariates considered for entry in the model were sex, age, body mass index, mean arterial pressure, $\gamma$-glutamyltransferase activity in serum, blood glucose, the serum concentration of total and HDL cholesterol, current smoking and antihypertensive drug treatment. We also repeated the analyses after excluding 26 occupationally exposed men, as well as in the whole study population after additionally adding total serum calcium, socio-economic status and energy spent in physical activity as covariates. Throughout this paper, all $p$ values refer to two-sided hypotheses.

\section{RESULTS}

\section{Characteristics of participants}

The mean (SD) age of the study participants $(n=557)$ was 44.1 (13.2) years (range 20.0-79.0). Table 1 summarises their demographic characteristics.

Median daily tobacco consumption of the low exposure group $(n=288)$ was 17 cigarettes (interquartile range (IOR) 12-22) in 41 male smokers and 15 cigarettes (IOR 12-20) in 37 female smokers. Similarly, the median daily tobacco consumption of the high exposure group $(n=269)$ was 15 cigarettes (IOR 7-21) in 47 male smokers and 15 cigarettes (IOR 10-21) in 48 female smokers. The median number of pack-years for the low exposure group was 14.5 (IOR 7.3-21.3) and 14.5 (IOR 5.5-22.0) for the high exposure group. During their lifetime, two men $(0.7 \%)$ from the low exposure group and 24 men (8.9\%) from the high exposure group had been occupationally exposed to cadmium. Grouped together, their $24 \mathrm{~h}$ urinary cadmium excretion was more than double that of men not occupationally exposed (geometric mean 20.6 (*1.75; 7.0-53.6) vs 8.4 (*2.0; 2.5-22.4) nmol/24 h; $\mathrm{p}<0.001$ ). In addition, $24 \mathrm{~h}$ urinary cadmium excretion was higher in men than in women (geometric mean 8.4 (*2.0; 2.5-22.4) vs 7.4 (*1.9; 2.6-21.3) $\mathrm{nmol} / 24 \mathrm{~h} ; \mathrm{p}=0.033$ ) and in ever than never smokers (geometric mean 8.9 ( $* 2.0 ; 2.9-26.0$ ) vs 7.5 (*1.9; 2.5-21.3) nmol/ $24 \mathrm{~h} ; \mathrm{p}=0.005$ ). After adjusting for sex, $24 \mathrm{~h}$ urinary cadmium excretion significantly increased with age in both the low and high exposure groups $(\mathrm{p}<0.001$; data not shown).

\section{Unadjusted analyses}

Blood cadmium concentration and $24 \mathrm{~h}$ urinary cadmium excretion were significantly higher, while total serum calcium was significantly lower, in the high exposure group. There were no differences in age, systolic, diastolic and mean arterial pressure between the groups (table 1).

Aortic pulse wave velocity was significantly lower in the high exposure group, while there was no difference in the anklebrachial index ( $p=0.25$; table 2$)$. The mean ankle-brachial index of both groups was well above 0.9. Values below 0.9 are indicative of peripheral arterial disease (table 2). ${ }^{24}$ Five subjects $(1.7 \%)$ from the low exposure group and three subjects $(1.1 \%)$ from the high exposure group had values below $0.9(p=0.18)$. 
Table 1 Baseline characteristics of the low and high exposure groups

\begin{tabular}{|c|c|c|c|}
\hline Characteristics & $\begin{array}{l}\text { Low exposure } \\
(n=288)\end{array}$ & $\begin{array}{l}\text { High exposure } \\
(\mathrm{n}=269)\end{array}$ & p Value \\
\hline \multicolumn{4}{|l|}{ Demographic characteristics } \\
\hline Women (\%) & 52.8 & 49.1 & \\
\hline Age (years) & 44.7(SD 13.3) & 43.5(SD 13.1) & 0.29 \\
\hline Body mass index $\left(\mathrm{kg} / \mathrm{m}^{2}\right)$ & $25.8(S D 3.6)$ & $26.0(S D 4.6)$ & 0.60 \\
\hline Systolic blood pressure $(\mathrm{mm} \mathrm{Hg})^{*}$ & 121.4(SD 14.3) & 120.4(SD 15.8) & 0.42 \\
\hline Diastolic blood pressure $(\mathrm{mm} \mathrm{Hg})^{*}$ & 71.8(SD 8.6) & 72.8(SD 8.2) & 0.14 \\
\hline Mean arterial pressure $(\mathrm{mm} \mathrm{Hg})^{*}$ & 88.3(SD 9.7) & 88.7(SD 9.8) & 0.68 \\
\hline Pulse rate (beats per minute) & 63.1(SD 9.5) & 61.6(SD 9.7) & 0.74 \\
\hline Socio-economic status & & & $<0.001$ \\
\hline Low, n (\%) & $207(72.6)$ & $228(84.8)$ & \\
\hline Medium, n (\%) & $67(23.3)$ & $41(15.2)$ & \\
\hline High, n (\%) & $12(4.2)$ & $0(0)$ & \\
\hline $\begin{array}{l}\text { Occupational exposure to } \\
\text { cadmium, } \mathrm{n}(\%)\end{array}$ & $2(0.07)$ & $24(8.9)$ & $<0.001$ \\
\hline Current smokers, n (\%) & $78(27.1)$ & $95(35.3)$ & 0.036 \\
\hline Alcohol use, n (\%) & $60(20.8)$ & $56(20.8)$ & $>0.99$ \\
\hline Physical activity (kcal per day) & $\begin{array}{l}518 \text { (*14; } \\
1-3391)\end{array}$ & $\begin{array}{l}486(* 16 ; \\
1-3897)\end{array}$ & 0.78 \\
\hline \multicolumn{4}{|l|}{ Measurements in blood } \\
\hline Glucose (mmol/l) & 4.9(SD 0.6) & $5.0(S D 1.1)$ & 0.17 \\
\hline Total cholesterol (mmol/l) & $5.7($ SD 1.0) & $5.8(\mathrm{SD} 1.1)$ & 0.51 \\
\hline HDL cholesterol (mmol/l) & $1.34(S D 0.37)$ & $1.28(S D 0.36)$ & 0.054 \\
\hline$\gamma$-Glutamyltransferase (U/I) & $\begin{array}{l}23.4 \text { (*1.9; } \\
10.0-67.6)\end{array}$ & $\begin{array}{l}27.5 \text { (* } 1.8 ; \\
11.0-74.1)\end{array}$ & 0.001 \\
\hline Serum total calcium $(\mathrm{mmol} / \mathrm{l})$ & $2.34(S D 0.11)$ & 2.31 (SD 0.09) & 0.001 \\
\hline Blood cadmium (nmol/l) & $6.3(\mathrm{SD} 2.1)$ & $8.7(\mathrm{SD} 2.1)$ & $<0.001$ \\
\hline \multicolumn{4}{|l|}{ Measurements in urine } \\
\hline Volume (ml) & 1542.4(SD 592.0 & ) 1554.8(SD 601.6) & 0.81 \\
\hline Creatinine (nmol/24 h) & 12.8(SD 3.8) & 11.7 (SD 3.7) & 0.50 \\
\hline Urinary cadmium (nmol/24 h) & $\begin{array}{l}7.1(* 1.9 ; \\
2.4-20.9)\end{array}$ & $\begin{array}{l}9.8 \text { (* } 2.0 ; \\
2.8-27.5)\end{array}$ & $<0.001$ \\
\hline
\end{tabular}

${ }^{*}$ Average of five sphygmomanometric readings at the brachial artery.

Data are arithmetic means (SD), geometric means (* SD; 5th to 95th percentile interval), or number of subjects (\%). $\mathrm{n}$ denotes number of subjects. HDL indicates high density lipoprotein.
Pulse pressure of the brachial artery was significantly lower in the high exposure group (table 2). Additionally, pulse pressure of the femoral artery was significantly lower and arterial distensibility and compliance significantly higher in the high exposure group compared with the low exposure group.

\section{Adjusted analyses}

In exploratory analyses, we studied the associations of measures of arterial function with cadmium exposure across quartiles of $24 \mathrm{~h}$ urinary cadmium excretion with adjustments applied for sex and age. Brachial pulse pressure decreased significantly ( $p$ for trend $=0.015$; fig 1) with increasing cadmium excretion with a similar trend for systolic blood pressure (non-significant, $\mathrm{p}$ for trend $=0.16$ ). There was no association between diastolic blood pressure and $24 \mathrm{~h}$ urinary cadmium excretion ( $\mathrm{p}$ for trend $=0.84$; fig 1 ). Furthermore, at the femoral artery, the local pulse pressure significantly decreased ( $p$ for trend $=0.018$ ) with higher $24 \mathrm{~h}$ urinary cadmium excretion, whereas femoral distensibility ( $p$ for trend $=0.008$ ) and compliance ( $p$ for trend $=0.007$ ) significantly increased (fig 2).

In multivariate-adjusted analyses, we investigated the potential associations between measures of arterial function and $24 \mathrm{~h}$ urinary cadmium excretion (table 3 ).

The data were first adjusted for sex and age (as in fig 1), and then adjusted further for additional significant covariates (body mass index, mean arterial pressure, $\gamma$-glutamyltransferase activity in serum, blood glucose, serum concentration of total and HDL cholesterol, current smoking and antihypertensive treatment). Systolic blood pressure and pulse pressure at the brachial artery significantly decreased with higher urinary cadmium excretion. These findings were consistent after partial adjustment for sex and age and after additional adjustments for the above-mentioned significant covariates (table 3). Similarly, aortic pulse wave velocity, along with pulse pressure of the carotid artery, showed independent and negative correlations with $24 \mathrm{~h}$ urinary cadmium excretion. Femoral pulse pressure also correlated negatively, whereas femoral distensibility and compliance correlated positively with $24 \mathrm{~h}$ urinary cadmium excretion.

Table 2 Arterial wall properties by exposure

\begin{tabular}{|c|c|c|c|c|c|}
\hline Properties & $\mathbf{n}$ & Low exposure & $\mathbf{n}$ & High exposure & p Value \\
\hline Aortic pulse wave velocity (m/s) & 255 & 7.08(SD 2.21) & 231 & 6.61(SD 1.59) & 0.008 \\
\hline Ankle-brachial index & 285 & $1.19(S D 0.35)$ & 268 & $1.17(S D 0.12)$ & 0.25 \\
\hline \multicolumn{6}{|l|}{ Common carotid artery } \\
\hline Diameter (mm) & 287 & 7.38(SD 0.96) & 268 & 7.24(SD 0.89) & 0.071 \\
\hline Distension $(\mu \mathrm{m})$ & 287 & 443.2(SD 132.4) & 268 & 433(SD 148.9) & 0.40 \\
\hline Pulse pressure $(\mathrm{mm} \mathrm{Hg})$ & 280 & 47.8(SD 10.3) & 260 & 46.4(SD 11.9) & 0.13 \\
\hline Compliance coefficient $\left(\mathrm{mm}^{2} / \mathrm{kPa}\right)$ & 280 & 0.86 (SD 0.32) & 260 & 0.86 (SD 0.33) & 0.75 \\
\hline Distensibility coefficient $\left(10^{-3} / \mathrm{kPa}\right)$ & 280 & 20.9(SD 8.4) & 260 & 21.3(SD 8.2) & 0.63 \\
\hline \multicolumn{6}{|l|}{ Brachial artery } \\
\hline Diameter (mm) & 281 & 4.17(SD 0.73) & 262 & 4.05(SD 0.73) & 0.056 \\
\hline Distension $(\mu \mathrm{m})$ & 281 & 283.7(SD 121.1) & 262 & 252.5(SD 94.9) & 0.001 \\
\hline Pulse pressure $(\mathrm{mm} \mathrm{Hg})$ & 288 & 49.7(SD 9.9) & 269 & 47.6(SD 11.8) & 0.026 \\
\hline Compliance coefficient $\left(\mathrm{mm}^{2} / \mathrm{kPa}\right)$ & 281 & $0.30(S D 0.14)$ & 261 & $0.27(S D 0.12)$ & 0.028 \\
\hline Distensibility coefficient $\left(10^{-3} / \mathrm{kPa}\right)$ & 281 & 22.9(SD 12.0) & 261 & 21.8(SD 9.8) & 0.26 \\
\hline \multicolumn{6}{|l|}{ Femoral artery } \\
\hline Diameter (mm) & 263 & 9.42(SD 1.31) & 239 & 9.19(SD 1.27) & 0.043 \\
\hline Distension ( $\mu \mathrm{m})$ & 263 & 236.7(SD 102.8) & 239 & 264.3(SD 114.7) & 0.005 \\
\hline Pulse pressure $(\mathrm{mm} \mathrm{Hg})$ & 256 & 53.8(SD 11.2) & 233 & $51.0(S D 12.1)$ & 0.008 \\
\hline Compliance coefficient $\left(\mathrm{mm}^{2} / \mathrm{kPa}\right)$ & 256 & 0.51 (SD 0.26) & 233 & 0.59 (SD 0.28) & 0.001 \\
\hline Distensibility coefficient $\left(10^{-3} / \mathrm{kPa}\right)$ & 256 & 7.63(SD 4.07) & 233 & $9.20(S D 4.53)$ & $<0.001$ \\
\hline
\end{tabular}

Data are arithmetic means (SD). $\mathrm{n}$ denotes number of subjects. 


- - - Low exposure $\longrightarrow$ High exposure

Brachial artery

Systolic blood pressure

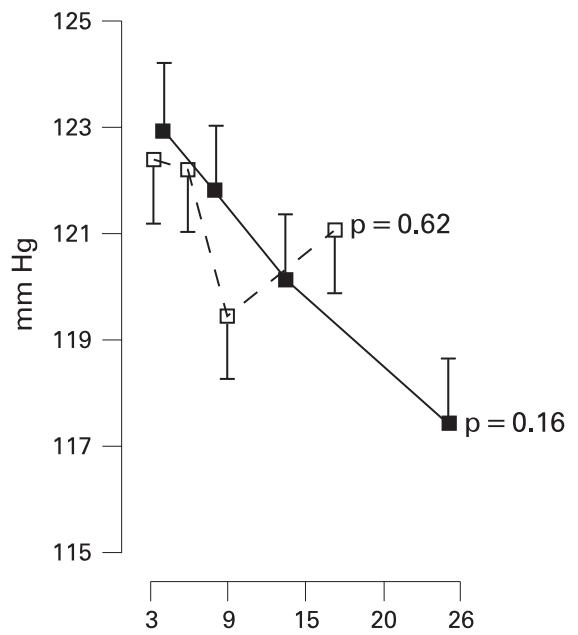

Diastolic blood pressure

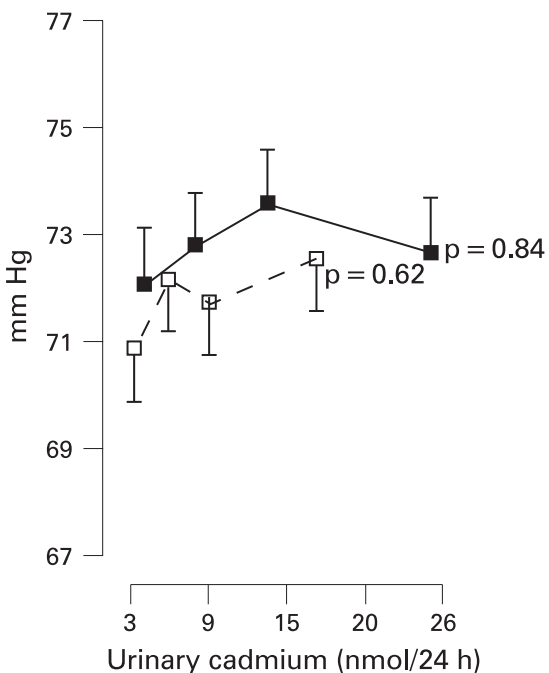

Pulse pressure

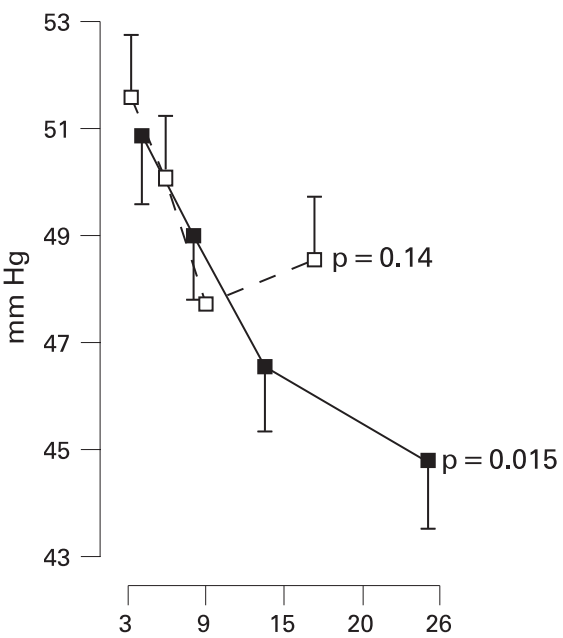

Figure 1 Brachial systolic, diastolic and pulse pressures by quartiles of $24 \mathrm{~h}$ urinary cadmium excretion. Plotted values are least squares means (SE) adjusted for sex and age in the low and high exposure groups. $p$ Value denotes significance for trend.

Although $24 \mathrm{~h}$ urinary cadmium excretion and blood cadmium correlated significantly $(\beta=0.63 \pm 0.04 ; p<0.01)$, no significant correlations could be obtained between measures of arterial function and blood cadmium (data not shown). The ankle-brachial index also failed to correlate with urinary or blood cadmium, irrespective of whether analysed as a continuous variable or dichotomised at a threshold of 0.9 .

\section{Sensitivity analyses}

In sensitivity analyses, we repeated the analyses by excluding 26 occupationally exposed men. We also computed in the whole study population the associations between arterial characteristics and $24 \mathrm{~h}$ urinary cadmium excretion after additionally adjusting for serum total calcium, socio-economic status and the energy spent in physical activity (table 4).

\section{- ㅁ - Low exposure $\longrightarrow-$ High exposure}

Femoral artery

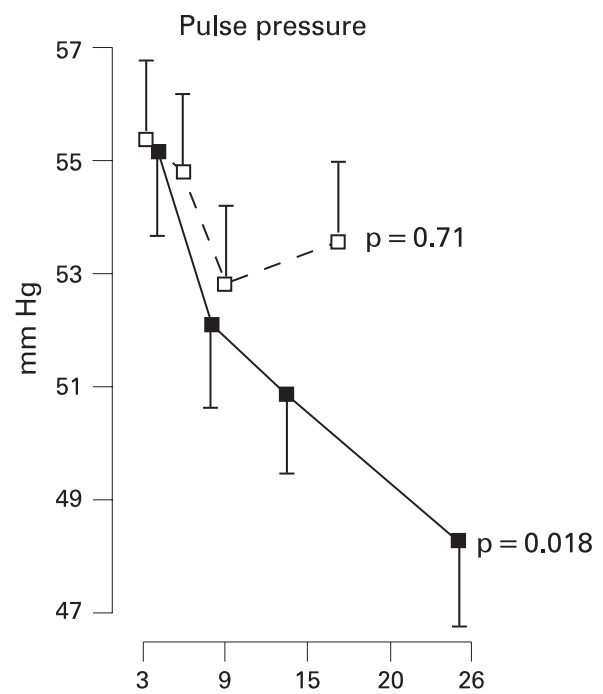

Compliance coefficient

Distensibility coefficient
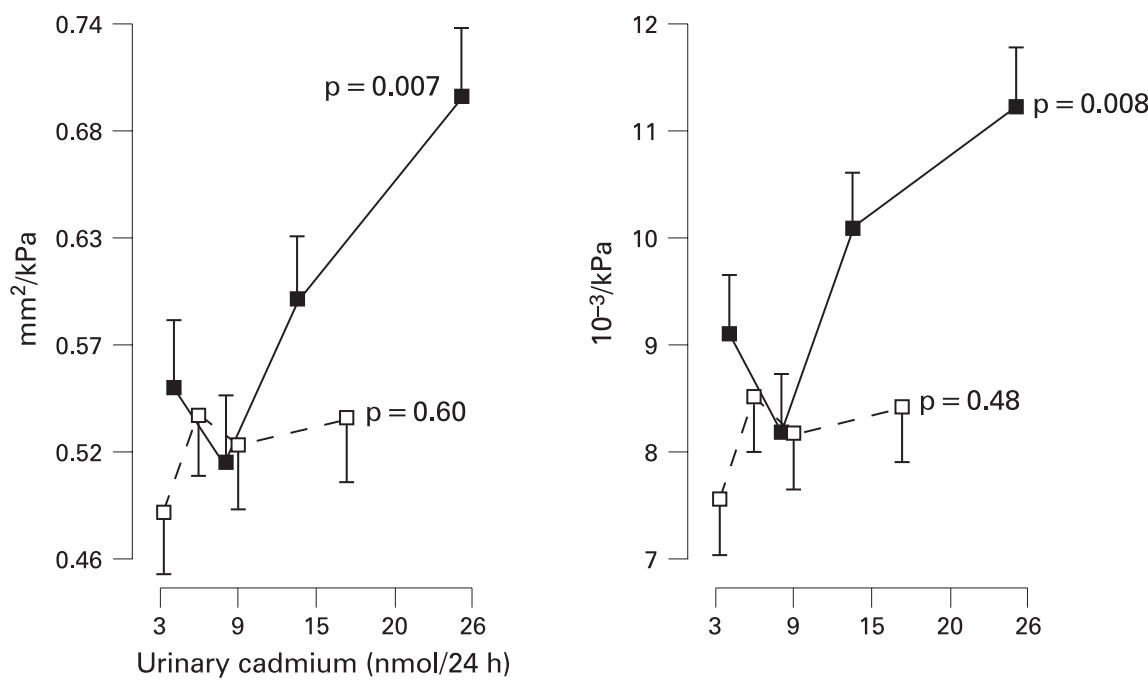

Figure 2 Femoral pulse pressure, distensibility and compliance by quartiles of $24 \mathrm{~h}$ urinary cadmium excretion. Plotted values are least squares means (SE) adjusted for sex and age in the low and high exposure groups. $p$ Value denotes significance for trend. 
Table 3 Partial regression coefficients between blood pressure, vessel wall properties and $24 \mathrm{~h}$ urinary cadmium excretion

\begin{tabular}{|c|c|c|c|c|c|}
\hline \multirow[b]{2}{*}{ Variable } & \multirow[b]{2}{*}{$\mathbf{n}$} & \multicolumn{2}{|c|}{ Adjusted for sex and age } & \multicolumn{2}{|l|}{ Fully adjusted* } \\
\hline & & Coefficient (SE) & p Value & Coefficient (SE) & p Value \\
\hline Systolic blood pressure $\dagger$ & 553 & $-5.21(2.19)$ & 0.018 & $-4.14(2.21)$ & 0.062 \\
\hline Mean arterial pressure $\dagger$ & 553 & $-0.52(1.46)$ & 0.72 & $-0.38(1.50)$ & 0.80 \\
\hline Aortic pulse wave velocity & 484 & $-0.65(0.28)$ & 0.019 & $-0.79(0.27)$ & 0.004 \\
\hline Ankle brachial index & 549 & $-0.01(0.04)$ & 0.80 & $-0.01(0.04)$ & 0.88 \\
\hline Compliance coefficient & 537 & $+0.08(0.04)$ & 0.078 & $+0.06(0.04)$ & 0.19 \\
\hline Distensibility coefficient & 537 & $+0.19(0.92)$ & 0.84 & $+0.05(0.86)$ & 0.96 \\
\hline \multicolumn{6}{|l|}{ Brachial artery } \\
\hline Pulse pressure & 553 & $-7.00(1.58)$ & $<0.001$ & $-5.43(1.41)$ & 0.001 \\
\hline Compliance coefficient & 538 & $+0.02(0.02)$ & 0.24 & $+0.02(0.02)$ & 0.34 \\
\hline Distensibility coefficient & 538 & $+0.94(1.76)$ & 0.59 & $+0.81(1.72)$ & 0.64 \\
\hline
\end{tabular}

${ }^{*}$ Adjusted for sex, age, body mass index, mean arterial pressure, $\gamma$-glutamyltransferase, blood glucose, total and high density lipoprotein cholesterol, current smoking and antihypertensive treatment.

†Unadjusted for mean arterial pressure.

$\mathrm{n}$ denotes number of subjects.

These analyses were in line with the main results and supported the inverse linear associations of $24 \mathrm{~h}$ urinary cadmium excretion with aortic pulse wave velocity and the carotid, brachial and femoral pulse pressures as well as the positive associations of $24 \mathrm{~h}$ urinary cadmium with the femoral compliance and distensibility coefficients.

\section{DISCUSSION}

We examined a population-based sample to determine to what extent the properties of large elastic and muscular arteries are associated with $24 \mathrm{~h}$ urinary cadmium excretion, the most reliable biomarker of lifetime exposure and cadmium body burden. The key and unexpected finding of our study is that increased cadmium body burden is not associated with decreased arterial function, as previously reported in peripheral leg arteries. ${ }^{11} 12$

Although cadmium is an environmental pollutant with high toxicity and is implicated in renal ${ }^{2-4}$ and bone ${ }^{5-7}$ disorders, as well as in the development of cancer at the population level, ${ }^{8}$ cadmium's influence on the cardiovascular system remains controversial. Cross-sectional and prospective studies by Staessen et $a^{1025}$ showed that cadmium does not increase conventional or $24 \mathrm{~h}$ ambulatory blood pressure, ${ }^{10}$ or the risk of hypertension or other cardiovascular disease ${ }^{25}$ in environmentally exposed populations. Subjects with Itai-Itai disease also failed to develop hypertension. ${ }^{26}{ }^{27}$ Kurihara et $a^{28}$ studied urinary cadmium normalised for creatinine as a biomarker of exposure and reported a significant odds ratio for hypertension less than unity in both men $(0.62(0.42-0.92))$ and women $(0.67(0.48-$ 0.94)).

Recently, Navas-Acien et $a l^{1112}$ reported that peripheral arterial disease might be associated with cadmium, thus suggesting that cadmium is involved in arterial dysfunction. The authors ${ }^{11} 12$ used the ankle-brachial index to reflect peripheral arterial disease. This non-invasive measure is useful in assessing the patency of the leg arteries ${ }^{29}{ }^{30}$ and predicts cardiovascular morbidity and mortality. ${ }^{31-33}$ However, this index is not representative of the major elastic and muscular arteries of the arterial system. The authors ${ }^{11}{ }^{12}$ also dichotomised anklebrachial index (which is a continuous variable) at a threshold level of $0.9 .{ }^{11}{ }^{12}$ This is indeed useful clinically but is not very informative epidemiologically because in populations this index is continuously distributed. Additionally, Navas-Acien et a $1^{11} 12$ estimated cadmium exposure from blood ${ }^{11}$ and spot urine ${ }^{12}$ samples. Blood cadmium concentrations mainly reflect recent exposure. $^{34} 35$ The cadmium concentration in spot urine samples, irrespective of whether it is normalised for creatinine or not, is inferior as a biomarker of the cadmium body burden. ${ }^{9}$

Table 4 Sensitivity analysis

\begin{tabular}{|c|c|c|c|c|c|c|}
\hline \multirow[b]{2}{*}{ Variable } & \multicolumn{3}{|c|}{ Only environmentally exposed* } & \multicolumn{3}{|c|}{ Total group $\dagger$} \\
\hline & $\mathbf{n}$ & Coefficient (SE) & p Value & $\mathbf{n}$ & Coefficient (SE) & p Value \\
\hline Aortic pulse wave velocity & 462 & $-0.77(0.28)$ & 0.007 & 484 & $-0.75(0.28)$ & 0.007 \\
\hline Carotid pulse pressure & 511 & $-3.73(1.57)$ & 0.018 & 537 & $-4.05(1.55)$ & 0.009 \\
\hline Brachial pulse pressure & 527 & $-4.95(1.46)$ & 0.001 & 553 & $-5.31(1.45)$ & 0.001 \\
\hline Femoral pulse pressure & 463 & $-4.20(1.80)$ & 0.019 & 486 & $-4.54(1.79)$ & 0.012 \\
\hline Femoral compliance coefficient & 463 & $+0.09(0.05)$ & 0.064 & 486 & $+0.09(0.05)$ & 0.042 \\
\hline Femoral distensibility coefficient & 463 & $+1.23(0.71)$ & 0.084 & 486 & $+1.55(0.72)$ & 0.031 \\
\hline
\end{tabular}

\footnotetext{
*These analyses exclude 26 occupationally exposed men.
}

$\dagger$ These analyses include the whole study population but were additionally adjusted for serum total calcium, socio-economic status and the energy spent in physical activity. All partial regression coefficients were adjusted for sex, age, body mass index, mean arterial pressure, $\gamma$-glutamyltransferase, blood glucose, total and high density lipoprotein cholesterol, current smoking and antihypertensive treatment. $n$ denotes number of subjects. 
Interestingly, our results did not show correlations between measures of arterial function and blood cadmium. However, our results failed to confirm that increased cadmium body burden (determined by $24 \mathrm{~h}$ urinary cadmium excretion) is associated with decreased arterial function. Aortic pulse wave velocity, which is the gold standard of arterial stiffness, ${ }^{36}$ was lower in the high exposure group (table 2). In addition, pulse pressure of the brachial artery was also lower in the high exposure group. Similarly, pulse pressure of the femoral artery was lower and femoral arterial compliance and distensibility were higher in the high exposure group. These results remained consistent in multivariate adjusted analyses (table 3). In an attempt to elaborate further on our results, we compared measures of arterial function of the brachial and femoral arteries across quartiles of exposure (figs 1 and 2). These analyses confirmed the associations with femoral pulse pressure, compliance and distensibility. Although systolic blood pressure did not differ between the high and low exposure groups, after adjusting for sex and age, it also became clear that the association between brachial pulse pressure and cadmium was due to cadmium's tendency to decrease systolic and not increase diastolic blood pressure (fig 1). This is in line with our previous findings showing an inverse association in men between systolic blood pressure and the blood cadmium concentration. ${ }^{25}$

Extrapolation from animals to humans is difficult. ${ }^{37}$ However, animal studies indicate that cadmium has a biphasic effect, that is, at low intracellular concentrations it causes vasoconstriction by stimulation of myosin light-chain kinase, whereas at high concentrations it induces vasodilation by inhibiting this enzyme..$^{38-41}$ Another possible explanation could be that cadmium is involved in the production of reactive oxygen species, such as hydrogen peroxide. ${ }^{42}$

Reactive oxygen species are implicated in the development of atherosclerosis, ${ }^{43}$ but hydrogen peroxide causes flow-induced dilation by acting as an endothelial-derived hyperpolarising factor. This has been shown in human coronary ${ }^{44}$ and mesenteric arteries. ${ }^{45}$ Chronic exposure to cadmium not only leads to its accumulation in the kidneys and liver but also in the endothelium and vascular smooth muscle cells. ${ }^{46}{ }^{47}$ One could speculate, although exposed to low environmental levels, that intracellular cadmium concentrations are sufficient to cause vasodilation in the high exposure group. On the other hand, if cadmium solely affected the endothelium and arterial smooth muscle cells to cause vasodilation, the effect would be primarily expected in muscular arteries, and not, or to a very limited extent, in elastic arteries. Our results did show associations with both elastic (aorta and carotid) and muscular (brachial and femoral) arteries. The possibility thus exists that cadmium not only affects the endothelium and arterial smooth muscle cells but could also interfere with the arterial matrix, such as by suppressing collagen fibril formation. ${ }^{48} 49$ This could indeed increase the elastin to collagen ratio and consequently increase distensibility.

The present study has to be interpreted within the context of its limitations and strengths. We applied a cross-sectional design to investigate the associations of measures of arterial function with $24 \mathrm{~h}$ urinary cadmium excretion and cannot infer causality. We cannot exclude that our associations obtained were due to residual confounding or were caused by some unknown factor that is associated with both arterial function and urinary cadmium. Also, our sample size was relatively small. Most subjects were examined in the non-fasting state. The requested $3 \mathrm{~h}$ interval of abstinence from drinking alcohol or caffeine-

\section{Main messages}

- An increased cadmium body burden is not associated with decreased arterial function. This was determined in large arteries that are representative of the arterial system, as opposed to an index that reflects the patency of leg arteries.

- These results are supportive of previous findings, where cadmium does not seem to increase conventional or $24 \mathrm{~h}$ blood pressure, or the risk of hypertension or other cardiovascular diseases.

- Nevertheless, the findings suggest that cadmium influences cardiovascular function even at environmental levels of exposure.

\section{Policy implications}

- The effect of environmental cadmium exposure on public health is once again highlighted. Emissions from non-ferrous smelters have stopped. However, these industrial sites are still polluted and are continuous sources of cadmium exposure. Cadmium reaches surrounding communities via lateral wind erosion of cadmium loaded soil, or by leaching of cadmium into groundwater.

- Preventative measures should be targeted. The precise transfer vector(s) must be identified and the soil in the immediate vicinity of these former smelters should be cleaned up without further delay.

containing beverages or heavy exercise might not have been long enough to standardise the arterial measurements fully.

We derived the local pulse pressures at the carotid and femoral arteries from the brachial pulse pressure. We do not believe that the consistent inverse association between local pulse pressure and $24 \mathrm{~h}$ urinary cadmium excretion at the three arterial sites was an artefact. Indeed, derivation of the local pulse pressure rests on the fact that diastolic blood pressure and mean arterial pressure are constant across the arterial tree. ${ }^{50}$ This physiological principle explains why trends in pulse pressure must be related at the three arterial sites. Furthermore, the ultrasonographic measurements of carotid, brachial and femoral diameter and distension were obtained in a manner which is truly independent. Mechanical properties of small and large muscular arteries differ. ${ }^{51}$ These local arterial characteristics explain why the associations of distension and distensibility with cadmium were not consistent at the brachial and femoral sites. In addition, only one highly trained specialist measured the arterial properties by means of a very sophisticated ultrasound technique, which in experienced hands has high intraobserver and interobserver reproducibility within and across sessions. ${ }^{52}$

To our knowledge, our study is the first to investigate associations between measures of arterial function from the main arterial tree (obtained by an ultrasound technique) and $24 \mathrm{~h}$ urinary cadmium excretion, the most reliable biomarker of lifetime exposure.

Cadium emissions (which took place since 1888) from the three local smelters dropped from $125000 \mathrm{~kg}$ in 1950 to $130 \mathrm{~kg}$ per year in $1989 . .^{33}$ The last cadmium refinery shut down in 2002. Because cadmium persists in the environment, the historical environmental pollution of the soil continues to be a source of low-level exposure. In spite of this continued 
pollution, the influence on cardiovascular morbidity and mortality seems negligible. Indeed, by using the standardised hazard ratios relating various cardiovascular outcomes to aortic pulse wave velocity, as determined by Hansen et al,, 54 our results suggested that a twofold increase in $24 \mathrm{~h}$ urinary cadmium excretion might be associated with a hazard ratio of 1.01 for a composite of all cardiovascular end points and cardiovascular mortality, as well as coronary heart disease.

In conclusion, increased cadmium body burden is associated with lower aortic pulse wave velocity, lower pulse pressure throughout the arterial system, and higher femoral distensibility. These findings need clarification in further prospective and mechanistic studies.

Acknowledgements: This study would not have been possible without the voluntary collaboration of participants and their general practitioners. The municipality of Hechtel-Eksel (Belgium) gave logistic support. The authors gratefully acknowledge the expert technical assistance of Sandra Covens, Linda Custers, Marie-Jeanne Jehoul, Katrien Staessen, Hanne Truyens and Renilde Wolfs (Studies Coordinating Centre, University of Leuven, Belgium).

Funding: The International Lead Zinc Research Organization (ILZRO) supported the study from 25 January 1990 to 24 February 1994. The European Union (grant LSHM-CT-2006-037093 InGenious HyperCare) and the Fonds voor Wetenschappelijk Onderzoek Vlaanderen, Ministry of the Flemish Community, Brussels, Belgium (grants OT/99/28, OT/00/25 and OT/05/49) provided support to the Studies Coordinating Centre. JAS is holder of the Pfizer Chair for Hypertension and Cardiovascular Research (http://www.kuleuven.be/mecenaat/leerstoelen/overzicht.htm).

Competing interests: HAR was a member of the scientific review panel (health) for the Voluntary Risk Assessment Report on Lead and Lead Compounds drafted by ILZRO (Research Triangle Park, NC, USA), the European Bio-Research Consultants (EBRC Consulting GmbH, Hannover, Germany) and the Lead Development Association International (LDAint, London, UK) in the framework of the EC Chemical Bureau Existing Substances Programme. All other authors declare no conflicts of interest.

\section{REFERENCES}

1. Järup $\mathbf{L}$, Berglund $M$, Elinder CG, et al. Health effects of cadmium exposure - a review of the literature and a risk estimate. Scand J Work Environ Health 1998;24(Suppl 1):1-51.

2. Staessen JA, Lauwerys RR, Ide G, et al. Renal function and historical environmental cadmium pollution from zinc smelters. Lancet 1994;343:1523-7.

3. Satarug S, Nishijo M, Lasker JM, et al. Kidney dysfunction and hypertension: role for cadmium, p450 and heme oxygenases? Tohoku J Exp Med 2006;208:179-202.

4. Buchet JP, Lauwerys R, Roels $\mathrm{H}$, et al. Renal effects of cadmium body burden of the general population. Lancet 1990;336:699-702

5. Staessen J, Amery A, Bernard A, et al. Effects of exposure to cadmium on calcium metabolism: a population study. Br J Ind Med 1991;45:710-14.

6. Kjellström T. Effects on bone, on vitamin D, and calcium metabolism. In: Friberg L, Elinder CG, Kjellström T, et al., eds Cadmium and health: a toxicological and epidemiological appraisal. Vol II. Effects and response. Boca Raton, FL: CRC Press, 1985:111-58.

7. Staessen JA, Roels HA, Emelianov D, et al. Environmental exposure to cadmium, forearm bone density, and risk of fractures: prospective population study. Lancet 1999;353:1140-4.

8. Nawrot T, Plusquin M, Hogervorst J, et al. Environmental exposure to cadmium and risk of cancer: a prospective population-based study. Lancet Oncol 2006;7:119-26.

9. Grandjean $\mathbf{P}$, Brown SS, Reavey $P$, et al. Biomarkers in environmental toxicology: state of the art. Clin Chem 1995;41:1902-29.

10. Staessen JA, Kuznetsova T, Roels HA, et al. Exposure to cadmium and conventional and ambulatory blood pressures in a prospective population study. Am J Hypertens 2000;13:146-56.

11. Navas-Acien A, Selvin E, Sharrett AR, et al. Lead, cadmium, smoking, and increased risk of peripheral arterial disease. Circulation 2004;109:3196-201.

12. Navas-Acien A, Silbergeld EK, Sharrett AR, et al. Metals in urine and peripheral arterial disease. Environ Health Perspect 2005;113:164-9.

13. Plusquin M, Nawrot TS, Staessen JA. Peripheral arterial disease and metals in urine and blood. Environ Health Perspect 2005;113:A510-11.

14. Hogervorst J, Plusquin M, Vangronsveld J, et al. House dust as possible route of environmental exposure to cadmium and lead in the adult general population. Environ Res 2007;103:30-7.

15. Office of Population Censuses and Surveys. Classification of occupations and coding index. London, UK: Her Majesty's Stationery Office, 1980.

16. McArdle WD, Katch FI, Katch VL. Exercise physiology. Energy, nutrition, and human performance. Philadelphia, PA: Lea and Febiger, 1991.

17. Balkestein EJ, Staessen JA, Wang JG, et al. Carotid and femoral artery stiffness in relation to three candidate genes in a white population. Hypertension 2001;38:1190-7.
18. Zebekakis PE, Nawrot T, Thijs L, et al. Obesity is associated with increased arterial stiffness from adolescence until old age. J Hypertens 2005;23:1839-46.

19. Kuznetsova T, Staessen JA, Kawecka-Jaszcz K, et al. Quality control of the blood pressure phenotype in the European Project on Genes in Hypertension. Blood Press Monit 2002; 7:215-24.

20. Van Bortel LM, Balkestein EJ, van Der Heijden-Spek JJ, et al. Non-invasive assessment of local arterial pulse pressure: comparison of applanation tonometry and echo-tracking. J Hypertens 2001;19:1037-44.

21. Hoeks AP, Reneman RS. Biophysical principles of vascular diagnosis. J Clin Ultrasound 1995;23:71-9.

22. Lauwerys R, Amery A, Bernard A, et al. Health effects of environmental exposure to cadmium: objectives, design and organization of the Cadmibel study: a crosssectional morbidity study carried out in Belgium from 1985 to 1989. Environ Health Perspect 1990;87:283-9.

23. Claeys F, Ducoffre G, Sartor F et al. Analytical quality control of cadmium and lead in blood and cadmium in urine: results of its implementation during a five-year epidemiological study. In: Nordberg GF, Herber RFM, Alessio L, eds. Cadmium in the human environment: toxicity and carcinogenicity. Lyon: International Agency for Research on Cancer, 1992:83-92.

24. Newman AB, Siscovick DS, Manolio TA, et al. Ankle-arm index as a marker of atherosclerosis in the Cardiovascular Health Study. Cardiovascular Heart Study (CHS) Collaborative Research Group. Circulation 1993;88:837-45.

25. Staessen J, Amery A, Bernard A, et al. Blood pressure, the prevalence of cardiovascular diseases and exposure to cadmium: a population study. Am J Epidemiol 1991;134:257-67.

26. Kjellström T. Appendix: Itai-Itai disease. In: Friberg L, Elinder CG, Kjellström T, et al., eds Cadmium and health: a toxicological and epidemiological appraisal. Vol II. Exposure, dose, and metabolism. Boca Raton, FL: CRC Press, 1985: 257-90.

27. Nakagawa H, Nishijo M. Environmental cadmium exposure, hypertension and cardiovascular risk. J Cardiovasc Risk 1996;3:11-17.

28. Kurihara I, Kobayashi E, Suwazono Y, et al. Association between exposure to cadmium and blood pressure in Japanese peoples. Arch Environ Health 2004;59:711-16.

29. Belch JJ, Topol EJ, Agnelli G, et al. Critical issues in peripheral arterial disease detection and management: a call to action. Arch Intern Med 2003;163 884-92.

30. Khan NA, Rahim SA, Anand SS, et al. Does the clinical examination predict lower extremity peripheral arterial disease? JAMA 2006;295:536-46.

31. Doobay AV, Anand SS. Sensitivity and specificity of the ankle-brachial index to predict future cardiovascular outcomes: a systematic review. Arterioscler Thromb Vasc Biol 2005;25:1463-9.

32. Resnick HE, Lindsay RS, McDermott MM, et al. Relationship of high and low ankle brachial index to all-cause and cardiovascular disease mortality: the Strong Heart Study. Circulation 2004;109:733-9.

33. Newman AB, Shemanski L, Manolio TA, et al. Ankle-arm index as a predictor of cardiovascular disease and mortality in the Cardiovascular Health Study. The Cardiovascular Health Study Group. Arterioscler Thromb Vasc Biol 1999;19: 538-45.

34. Bernard A, Lauwerys R. Cadmium in human population. Experientia 1984;40:143-52.

35. Nordberg GF, Kjellström T, Nordberg M. Kinetics and metabolism. In: Friberg L, Elinder CG, Kjellström T, et al, eds. Cadmium and health: a toxicological and epidemiological appraisal. Vol I. Exposure, dose, and metabolism. Boca Raton, FL: CRC Press, 1985:103-78.

36. Laurent S. Surrogate measures of arterial stiffness: do they have additive predictive value or are they only surrogates of a surrogate? Hypertension 2006;:47:325-6.

37. Staessen JA, Lauwerys RR, Bulpitt CJ, et al. Is a positive association between lead exposure and blood pressure supported by animal experiments? Curr Opin Nephrol Hypertens 1994;3:257-63.

38. Niwa A, Suzuki A. Effects of cadmium on the tension of isolated rat aorta la possible mechanism for cadmium-induced hypertension). J Toxicol Sci 1982; 7:51-60.

39. Kostrzewska A, Laudanski T, Bergelin I. Influence of cadmium ions on the reactivity of isolated human uterine arteries. J Toxicol Environ Health 1991;34: 187-95.

40. Wakabayashi I, Sakamoto K, Hatake K. Inhibitory effects of cadmium ion on extracellular $\mathrm{Ca}(2+)$-independent contraction of rat aorta. Eur J Pharmacol 1995:293:133-40.

41. Chao SH, Bu CH, Cheung WY. Stimulation of myosin light-chain kinase by $\mathrm{Cd} 2+$ and Pb2+. Arch Toxicol 1995;69:197-203.

42. Stohs SJ, Bagchi D, Hassoun E, et al. Oxidative mechanisms in the toxicity of chromium and cadmium ions. J Environ Pathol Toxicol Oncol 2001;20:77-88.

43. Mugge A. The role of reactive oxygen species in atherosclerosis. $Z$ Kardiol 1998;87:851-64.

44. Miura H, Bosnjak JJ, Ning G, et al. Role for hydrogen peroxide in flow-induced dilation of human coronary arterioles. Circ Res 2003;92:e31-e40.

45. Matoba T, Shimokawa $\mathrm{H}$, Kubota $\mathrm{H}$, et al. Hydrogen peroxide is an endotheliumderived hyperpolarizing factor in human mesenteric arteries. Biochem Biophys Res Commun 2002;290:909-13.

46. Baranski B, Opacka J, Wronska-Nofer T, et al. Effect of cadmium on arterial blood pressure and lipid metabolism in rats. Toxicol Lett 1983;18:245-50. 
47. Baranski B, Opacka J, Wronska-Nofer T, et al. Effect of inhalation exposure to cadmium oxide on arterial blood pressure, lipid metabolism and tissue cadmium concentration in rats. Med $\operatorname{Pr}$ 1983;34:11-19.

48. Terpin T, Roach MR. The effects of cadmium on the structure and elastic properties of carotid arteries from rats. J Environ Pathol Toxicol 1980;3:449-64.

49. Hojima Y, Behta B, Romanic AM, et al. Cadmium ions inhibit procollagen C-proteinase and cupric ions inhibit procollagen N-proteinase. Matrix Biol 1994;14:113-20.

50. Kool MJ, van Merode T, Reneman RS, et al. Evaluation of reproducibility of a vessel wall movement detector system for assessment of large artery properties. Cardiovasc Res 1994;28:610-14.
51. Van Bortel LM, Balkestein EJ, van der Heijden-Spek JJ, et al. Non-invasive assessment of local arterial pulse pressure: comparison of applanation tonometry and echo-tracking. J Hypertens 2001;19:1037-44.

52. O'Rourke M, Mancia G. Arterial stiffness. J Hypertens 1999;17:1-4.

53. Staessen JA, Lauwerys RR, Ide G, et al. Renal function and historical environmental cadmium pollution from zinc smelters. Lancet 1994;343: 1523-7.

54. Hansen TW, Staessen JA, Torp-Pedersen C, et al. Prognostic value of aortic pulse wave velocity as index of arterial stiffness in the general population. Circulation 2006;113:664-70.

\section{Echo}

\section{New test discloses inflammation in asbestosis non- invasively}

At last it is possible to assess lung inflammation non-invasively in patients with asbestosis, say researchers, by looking for raised exhaled nitric oxide (NO) and inflammatory markers in exhaled breath condensate. In time this might become a diagnostic criterion, they speculate.

They found significantly raised concentrations of $\mathrm{NO}$, corresponding to alveolar $\mathrm{NO}$, in patients versus controls when measured by multiple exhalation flow rates, but not the single standard flow rate recommended by the American Thoracic Society (ATS). They also found-for the first time in patients with asbestosis-high amounts of leucotriene B4 and 8-isoprostane in exhaled breath condensate compared with controls. Serum inflammatory markers C-reactive protein, interleukin- 6 and myeloperoxidase were also raised.

These results came from 15 non-smoking patients with asbestosis, mean age 62 years, average age at exposure to asbestos 20.5 years, on average 25.6 years ago, and the same number of healthy non-smoking age and sex matched controls. Subjects who smoked or who had asthma or other inflammatory lung diseases were excluded.

Raised exhaled NO indicates lung inflammation. Multiple flow measurement can discriminate bronchial from alveolar NO and asthma and alveolitis, the researchers have previously shown. COPD and alveolitis have also been separated in this way.

Knowing that inflammation of the lung parenchyma is a cardinal feature of asbestosis, the researchers reasoned that alveolar NO would be raised. Before now, only invasive procedures could assess inflammation in this condition. More work should tell whether the method can evaluate disease progression and influence of anti-inflammatory treatment.

- Lehtonen H, Oksa P, Lehtimäki L et al. Increased alveolar nitric oxide concentration and high levels of leukotriene $B_{4}$ and 8-isoprostrane in exhaled breath condensate in patients with asbestosis. Thorax 2007;62:602-7. 